\title{
Parameters Affecting the Microwave-Assisted Polyol Synthesis of Silver Nanorods
}

\author{
Srichandana Nandikonda and Edward W. Davis \\ Department of Polymer and Fiber Engineering, Auburn University, Auburn, AL 36849, USA \\ Correspondence should be addressed to Edward W. Davis, ewd0001@auburn.edu
}

Received 19 July 2011; Accepted 24 August 2011

Academic Editor: D. K. Sarker

Copyright ( $) 2011$ S. Nandikonda and E. W. Davis. This is an open access article distributed under the Creative Commons Attribution License, which permits unrestricted use, distribution, and reproduction in any medium, provided the original work is properly cited.

\begin{abstract}
The effects of salt chemistry and concentration on the morphology and yield of silver nanorods produced by the microwave-assisted polyol synthesis are reported. Compared to $\mathrm{NaCl}$, iron and copper salts reduced nanorod yield and length and increased diameter. This is in stark contrast to expectations based on the slower traditional polyol process. The role of the cation was further explored using $\mathrm{MgCl}_{2}$ and $\mathrm{MnCl}_{2}$ which showed different concentration dependent effects on nanorod diameter. In addition, the morphology and yield of nanomaterials was found to be significantly influenced by small variations in the procedure including container shape and the time between reactant mixing and microwave heating. These results highlight that, while the microwaveassisted process is very promising, results cannot be directly anticipated based on the traditional process, and the synthesis is very sensitive to procedural changes.
\end{abstract}

\section{Introduction}

In the last ten years, there has been significant interest in discovering scaleable routes for producing inorganic nanorods and nanowires. Common routes include the use of supercritical $\mathrm{CO}_{2}$, synthesis in surfactant templated systems $[1,2]$, and directed growth methods such as the polyol process. While many methods have been published in the literature, reproducibility, particularly with regard to shape, size, and yield has been an ongoing challenge [3]. For example, the seed-mediated, surfactant-assisted synthesis of gold [4] was first reported in 2001. However, researchers were initially frustrated in reproducing results. It took over nine years to understand the effects of seed aging time [5], method of mixing the seed and growth solutions [5], variations in salt concentration, temperature, growth time [6,7], and even trace impurities of iodide in the cetyltrimethylammonium bromide $(\mathrm{CTAB})$ surfactant $[3,8]$ on the yield, shape, and size of the resulting nanoparticles.

Similarly, the microwave-assisted polyol process has shown promise for producing a broad range of spherical nanoparticles, nanowires, and other shapes. However, there has been little exploration on how changes in reactants and pro- cedure affects shape and yield. There is ongoing interest in silver nanomaterials due to silver's antimicrobial properties. In addition, the size-dependent surface plasmon resonance (SPR) and local electric field strength combined with chemical sensitivity make silver attractive for chemical sensing applications based on surface-enhanced Raman-scattering (SERS) $[9,10]$. More recently, silver nanorods and nanowires have also garnered significant interest for electronics. Silver's high electrical conductivity $\left(63.0 \times 10^{6} \mathrm{~S} / \mathrm{m}\right.$ for Ag versus $60.7 \times 10^{6} \mathrm{~S} / \mathrm{m}$ for $\mathrm{Cu}$ ) makes silver nanowires interesting for interconnects [11]. This high conductivity coupled with the transparency that can be achieved at smallsize scales also makes nanosilver based-materials promising candidates for the flexible electrodes needed in advanced displays, touch screens, and the next generation of solar cells [12]. Another application where one-dimensional silver nanostructures are beneficial is in the development of thermally and electrically conductive composites. Currently these materials utilize silver flake [13]; replacing the flake with silver nanowires could significantly reduce the loading required to achieve geometric percolation and reduce the cost of these materials. In these and other applications, size and shape of the nanomaterials are critical parameters that determine 
performance. The percolation threshold of composite materials is directly related to the size and shape of the filler; smaller-diameter longer rods have a much lower percolation threshold than shorter larger-diameter rods. Transparency and flexibility of composite electrodes are dependent on the aspect ratio of the nanorods utilized. To commercially realize the potential applications of silver nanorods, it will be necessary to synthesize them at reasonable yields with control over size and shape. Ideally, the synthesis should be simple to perform and should not require the use of exotic reactants or conditions.

Several approaches have been explored for the production of silver nanowires including the use of nanoporus templates [14], hydrothermal synthesis [15], DNA templating [16], and wet chemical synthesis methods including the polyol process $[4,11,17]$. Most of these processes are complicated, and some do not produce products that are suitable for use in many applications. For example, the nanoporus templating process shows good control over the diameter but results in polycrystalline rods that strongly adhere to one another. As a result, dispersion of the nanoparticles in solution or within a polymer matrix is difficult. In contrast, the nanorods produced by the polyol process are easily separated from one another making them suitable for many applications. In the polyol process $\mathrm{Ag}^{+}$is reduced to $\mathrm{Ag}^{0}$ by acetaldehyde which is generated by the thermal decomposition of a polyol, usually ethylene glycol, at the reaction temperature [18]. The reduced silver nucleates and grows by Oswald ripening and diffusion of newly reduced silver to the surface. Polyvinyl pyrrolidone (PVP) helps to stabilize the growing particles and directs growth in one direction by preferentially coordinating with one of the crystal faces limiting crystal growth in directions normal to that face. While the polyol process can be utilized to produce easily separable nanorods, the standard process requires careful control over reaction rates to tailor particle geometry. Several morphologies can be produced by controlling reaction conditions such as the concentration of $\mathrm{Cl}^{-}$and $\mathrm{H}^{+}$, temperature, presence or absence of $\mathrm{O}_{2}$, and by controlling the reaction rate by dropwise addition of reactants $[19,20]$. In addition, several "control" agents have been examined in the polyol process for their ability to control particle geometry. Fe(II) was reported by Wiley et al. to control the reaction through the oxidative etching of the silver seeds [19]. Chen et al. later demonstrated the reduction in silver nanowire diameter by the addition of $\mathrm{Fe}\left(\mathrm{NO}_{3}\right)_{3}[21]$. This effect was explained through the process of etching the silver surface, the removal of oxygen from the surface, or the ability of metals with multiple valence states to affect the overall rate of reduction of $\mathrm{Ag}^{+}$. Other control agents that have been examined include salts of potassium, copper, and palladium and sodium sulfate [19, 21-23].

Recently there has been a significant interest in utilizing microwave heating to speed reaction rates and reduce the need for expensive catalyst [24]. Gou et al. demonstrated that a microwave-based polyol synthesis of silver nanorods can be completed in less than five minutes compared to several hours in the traditional process [25]. However, while several control agents have been explored in the traditional process, only $\mathrm{NaCl}$ and $\mathrm{NaS}$ have been examined in the microwave- assisted process $[25,26]$. The anions form $\mathrm{AgCl}$ salts or $\mathrm{Ag}_{2} \mathrm{~S}$ colloids and limit the amount of $\mathrm{Ag}^{+}$ions present in the solution that can be reduced to $\mathrm{Ag}^{0}$. This effectively controls the overall formation of $\mathrm{Ag}^{0}$, thus, allowing for directed growth to occur without the continued formation of new nuclei. In the case of $\mathrm{Na}_{2} \mathrm{~S}$, a wide variety of shapes including rods and cubes have been synthesized. Several studies on the traditional polyol process have found that significant control over the rod morphology can be obtained by utilizing different metal chlorides, $\mathrm{FeCl}_{3}, \mathrm{CuCl}_{2}$, and $\mathrm{KCl}$, for example. However, to date only sodium has been evaluated as the cation in the microwave-assisted process. This work extends understanding of how to control the synthesis of silver nanorods in the microwave-assisted polyol process. A range of salts were evaluated including $\mathrm{NaCl}, \mathrm{KCl}, \mathrm{MgCl}_{2}, \mathrm{CaCl}_{2}$, $\mathrm{CuCl}_{2}, \mathrm{FeCl}_{3}$, and $\mathrm{MnCl}_{2}$. The results indicate that some salts that are advantageous in the slower process are not suitable for the microwave-assisted process and that a previously unreported salt, $\mathrm{MnCl}_{2}$, is capable of producing small-diameter nanorods with a high aspect ratio.

\section{Experimental}

2.1. Materials and Equipment. Silver nitrate $\left(\mathrm{AgNO}_{3}\right)$ ( $>99 \%$ ) was purchased from Sigma-Aldrich, Poly(vinyl pyrrolidone) $(\mathrm{PVP})(\mathrm{M} . \mathrm{W} .=58000)$ from Acros Organics, salts $\left(\mathrm{NaCl}, \mathrm{KCl}, \mathrm{CaCl}_{2}, \mathrm{FeCl}_{3}, \mathrm{CuCl}_{2}, \mathrm{MnCl}_{2}\right.$, and $\left.\mathrm{MgCl}_{2}\right)$ and ethylene glycol (EG) were purchased from Fisher-Scientific and used as received. Two microwaves were used in this work, a commercially available household microwave (General Electric model JES1855) and a $3200 \mathrm{~W}$ continuously variable power microwave from Microwave Research Labs (model BP 211). Three reaction vessel geometries were evaluated: a $5 \mathrm{~cm}$ diameter glass beaker, a $7 \mathrm{~cm}$ diameter glass beaker, and $10 \mathrm{~cm}$ diameter glass dish.

2.2. Methods. Figure 1 shows the schematic representation of the synthesis process used in this study. Three stock solutions were prepared separately: $\mathrm{AgNO}_{3}$ in EG $(0.026 \mathrm{M})$, PVP in EG $(0.05 \mathrm{M})$, and salt solution (various concentrations). All stock solutions were prepared just prior to use and sonicated for 5 minutes to aid dissolution and ensure uniform dispersion of the solutes. After preparation of the three solutions, $20 \mathrm{~mL}$ of the $\mathrm{AgNO}_{3}$ solution was placed in the reaction vessel followed immediately by $20 \mathrm{~mL}$ of the PVP solution and then by $20 \mathrm{~mL}$ of the salt solution; the total reaction volume was $60 \mathrm{~mL}$. For all experiments, except investigations of container shape, the reaction vessel was a $300 \mathrm{~mL}$ glass container $5 \mathrm{~cm}$ in diameter. Immediately upon the addition of the salt solution, the entire dispersion became opaque with an opalescent color due to the formation of $\mathrm{AgCl}$ colloidal particles. The dispersion was mixed by swirling the container for 10-15 seconds followed by bubbling dry $\mathrm{N}_{2}$ through the container at a flow rate of $50 \mathrm{cc} / \mathrm{min}$ for $1 \mathrm{~min}$. The dispersion was then transferred to the microwave. When the household microwave was used, the power setting was at level 4 resulting in pulsed power of 13 seconds on and 17 seconds off. Tests with water indicated that the average delivered power under these conditions was $350 \mathrm{~W}$. Total microwave 


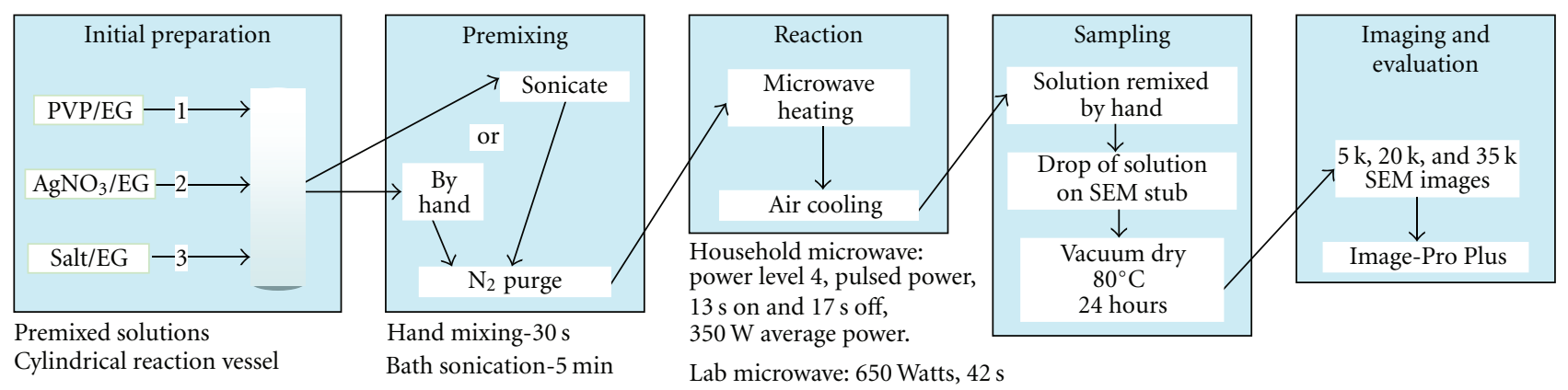

FIGURE 1: Schematic representation of synthesis, sample preparation, and evaluation processes used in this work.

time in this case was 2 minutes (four full cycles). The rotating turntable was off during the heating process. The laboratory microwave from Microwave Research Labs had continuous power control; when this oven was used, the power level was adjusted to $650 \mathrm{~W}$ and the reaction time was limited to $42 \mathrm{sec}$. Upon completion of the reaction, the dispersions were allowed to cool in air for 30 minutes. Samples were taken immediately after cooling for characterization.

2.3. Characterization. The reaction product was mixed by swirling the container for 30 seconds just prior to sampling with a disposable transfer pipet. Drops of the reaction product were placed on aluminium stubs coated with carbon tape and vacuum dried at $80^{\circ} \mathrm{C}$ for 24 hours to remove EG. The samples were imaged using a JEOL 7000 field-emission scanning electron microscope (SEM) without sputter coating. Since the coating on the nanorods, PVP, is not conductive, there is some hazing of the rod edges. High-magnification images ( $35 \mathrm{k}$ magnification) were used to determine rod diameters. To measure length, lower-magnification images $(5 \mathrm{k}$ magnification) were used. The number of nanorods present in a 2 by 3 micron grid was determined in a $20 \mathrm{k}$ magnification image and used as an indication of rod yield. All rods that intersected the measurement area were counted. At least three images were taken at each magnification, for each sample to account for sample variability across the stub. In some work, optical imaging was used to determine a rod/particle ratio. For this analysis, images were taken on Nikon Eclipse $80 \mathrm{i}$ at $60 \mathrm{x}$ magnification with $1.4 \mathrm{NA}$. These images were analyzed using Image Pro to determine the number of rods and particles in a fixed area.

\section{Results and Discussion}

3.1. Effect of Salt Concentration. Four salts, $\mathrm{NaCl}, \mathrm{KCl}$, $\mathrm{MgCl}_{2}$, and $\mathrm{CaCl}_{2}$, were tested to determine the effect of changing the cation within group I and II elements on the rod diameter, length, and nominal yield. Gou reported that the most favourable $\mathrm{Cl}^{-}$to $\mathrm{AgNO}_{3}$ ratio for the microwareassisted synthesis was between $1: 6$ and $1: 3$ by mole when using $\mathrm{NaCl}$ as the salt [25]. Therefore, for $\mathrm{NaCl}$ and $\mathrm{KCl}$, a $\mathrm{Cl}^{-}: \mathrm{AgNO}_{3}$ ratio of 1:6 was evaluated. For $\mathrm{MgCl}_{2}$ and $\mathrm{CaCl}_{2}$, both $1: 6$ and $1: 3$ ratios were evaluated. Figure 2 shows representative samples of the highest-magnification SEM images taken; these images, with others, were used to evaluate the rod diameter. Table 1 provides the diameters, lengths, and rod counts for all salts evaluated in this study. Of the four salts evaluated from group I and II, $\mathrm{MgCl}_{2}$ resulted in the smallest-diameter rods. The rod diameters were 38, 36 , and $31 \mathrm{~nm}$ for $\mathrm{NaCl}, \mathrm{KCl}$, and $\mathrm{MgCl}_{2}$, respectively. In contrast to the reduction in rod diameter achieved by changing the salt to $\mathrm{MgCl}_{2}$, use of $\mathrm{CaCl}_{2}$ resulted in larger diameter rods and a significant increase in the polydispersity of the rod diameters.

Both Wiley and Korte's work demonstrated that both the cation and the anion play a role in the formation and growth of silver nanowires $[19,23]$. The anion, $\mathrm{Cl}^{-}$, is thought to act as an electrostatic stabilizer for the initially formed seeds and has also been postulated to limit the availability of $\mathrm{Ag}^{+}$ ions, thereby, controlling the overall reduction of $\mathrm{Ag}^{+}$to $\mathrm{Ag}^{0}$ allowing directed growth to occur. These effects suggest that larger concentration would be more favourable. On the other hand, high concentration of $\mathrm{Cl}^{-}$ion leads to etching of twinned seeds, suggesting an optimum concentration range for $\mathrm{Cl}^{-}$. In this study, at least two concentrations of salt were tested for those cations with a valance greater than one. For the divalent materials, tests were performed with the ratio of $\mathrm{Cl}^{-}$to $\mathrm{Ag}$ at both $1: 3$ and $1: 6$; these are the limits suggested by Gou as the "best" for forming Ag nanorods in the microwave-assisted process [25]. In the case of $\mathrm{Fe}$, the $\mathrm{Cl}^{-}$to $\mathrm{Ag}$ ratios tested were $1: 6$ and $1: 2$. As shown in Table 1 , in every case higher $\mathrm{Cl}^{-}$concentrations resulted in fewer rods. In fact, at the higher of the two concentration for $\mathrm{FeCl}_{3}$ evaluated, no rods were formed. The effect of concentration on the rod diameter and length was less clear. For group I and II elements at a $\mathrm{Cl}^{-}$to $\mathrm{AgNO}_{3}$ ratio of $1: 6$, the longest rods were obtained from $\mathrm{KCl}$, and the highest number of rods was obtained from $\mathrm{NaCl}$. Changing the $\mathrm{Cl}^{-}$to $\mathrm{Ag}$ ratio to $1: 3$ for $\mathrm{MgCl}_{2}$ and $\mathrm{CaCl}_{2}$ affected the diameter, length, and rod number. Higher $\mathrm{MgCl}_{2}$ concentrations resulted in significantly fewer, much shorter, and smaller diameter rods, aspect ratio $(\mathrm{AR}) \sim 46$. A similar change with $\mathrm{CaCl}_{2}$, however, resulted in fewer, slightly longer, smaller-diameter rods, AR $\sim 237$.

In the traditional polyol process, the presence of disassociated $\mathrm{O}_{2}$ on the seed surface blocks the further deposition of Ag, limiting seed growth [19]. Korte et al. limited this effect by adding cations with multiple valence states, $\mathrm{Fe}^{+3}$ and $\mathrm{Cu}^{+2}$, which are capable of scavenging oxygen from the growing silver surface resulting in faster growth and longer 


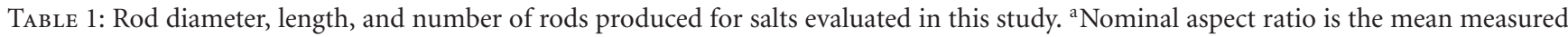
length divided by the mean diameter. ${ }^{\text {b }}$ The number of rods intersecting a 2 by 3 micron grid, multiple images taken at various location on stub.

\begin{tabular}{|c|c|c|c|c|c|c|c|c|}
\hline \multirow[b]{2}{*}{ Salt } & \multirow[b]{2}{*}{$\begin{array}{c}\text { Atomic radius } \\
(\text { metal })(\mathrm{pm})\end{array}$} & \multicolumn{2}{|c|}{ Concentration (mM) } & \multirow[b]{2}{*}{$\begin{array}{c}\mathrm{Cl}: \mathrm{AgNO}_{3} \\
\text { ratio }\end{array}$} & \multicolumn{4}{|c|}{ Ag rod properties (mean and Std. Dev.) } \\
\hline & & Metal & Chlorine & & $\begin{array}{l}\text { Diameter } \\
(\mathrm{nm})\end{array}$ & $\begin{array}{l}\text { Length } \\
(\mu \mathrm{m})\end{array}$ & $\begin{array}{c}\text { Nominal } \\
\mathrm{AR}^{\mathrm{a}}\end{array}$ & $\begin{array}{l}\text { No. of } \\
\text { rods }{ }^{\text {b }}\end{array}$ \\
\hline $\mathrm{NaCl}$ & 186 & 4.3 & 4.3 & $1: 6$ & $38.6(9.1)$ & $7.6(1.1)$ & 197 & $60(9)$ \\
\hline $\mathrm{KCl}$ & 227 & 4.3 & 4.3 & $1: 6$ & $35.6(9.0)$ & $9.1(1.3)$ & 255 & $51(4)$ \\
\hline \multirow{2}{*}{$\mathrm{MgCl}_{2}$} & \multirow{2}{*}{160} & 2.15 & 4.3 & $1: 6$ & $31.4(4.5)$ & $3.7(1.2)$ & 118 & $49(9)$ \\
\hline & & 4.3 & 8.6 & $1: 3$ & $26.1(6.7)$ & $1.2(0.3)$ & 46 & $12(3)$ \\
\hline \multirow{2}{*}{$\mathrm{CaCl}_{2}$} & \multirow{2}{*}{197} & 2.15 & 4.3 & $1: 6$ & $41.0(13.2)$ & $7.4(1.5)$ & 180 & $58(9)$ \\
\hline & & 4.3 & 8.6 & $1: 3$ & $35.8(8.8)$ & $8.5(1.4)$ & 237 & $30(3)$ \\
\hline \multirow{2}{*}{$\mathrm{MnCl}_{2}$} & \multirow{2}{*}{127} & 2.15 & 4.3 & $1: 6$ & $31.9(8.6)$ & $8.4(1.4)$ & 263 & $61(6)$ \\
\hline & & 4.3 & 8.6 & $1: 3$ & $41.8(10.5)$ & $7(1.8)$ & 167 & $29(3)$ \\
\hline \multirow{2}{*}{$\mathrm{FeCl}_{3}$} & \multirow{2}{*}{126} & 1.43 & 4.3 & $1: 6$ & $57.3(17.8)$ & $0.5(0.2)$ & 9 & $23(6)$ \\
\hline & & 4.3 & 12.9 & $1: 2$ & \multicolumn{4}{|c|}{ No rods found } \\
\hline \multirow[t]{2}{*}{$\mathrm{CuCl}_{2}$} & \multirow[t]{2}{*}{128} & 2.15 & 4.3 & $1: 6$ & $\begin{array}{l}118.8 \\
(52.7)\end{array}$ & $2.7(1.3)$ & 23 & $13(2)$ \\
\hline & & 4.3 & 8.6 & $1: 3$ & $\begin{array}{l}168.7 \\
(48.4)\end{array}$ & $1.3(0.6)$ & 8 & $9(1)$ \\
\hline
\end{tabular}
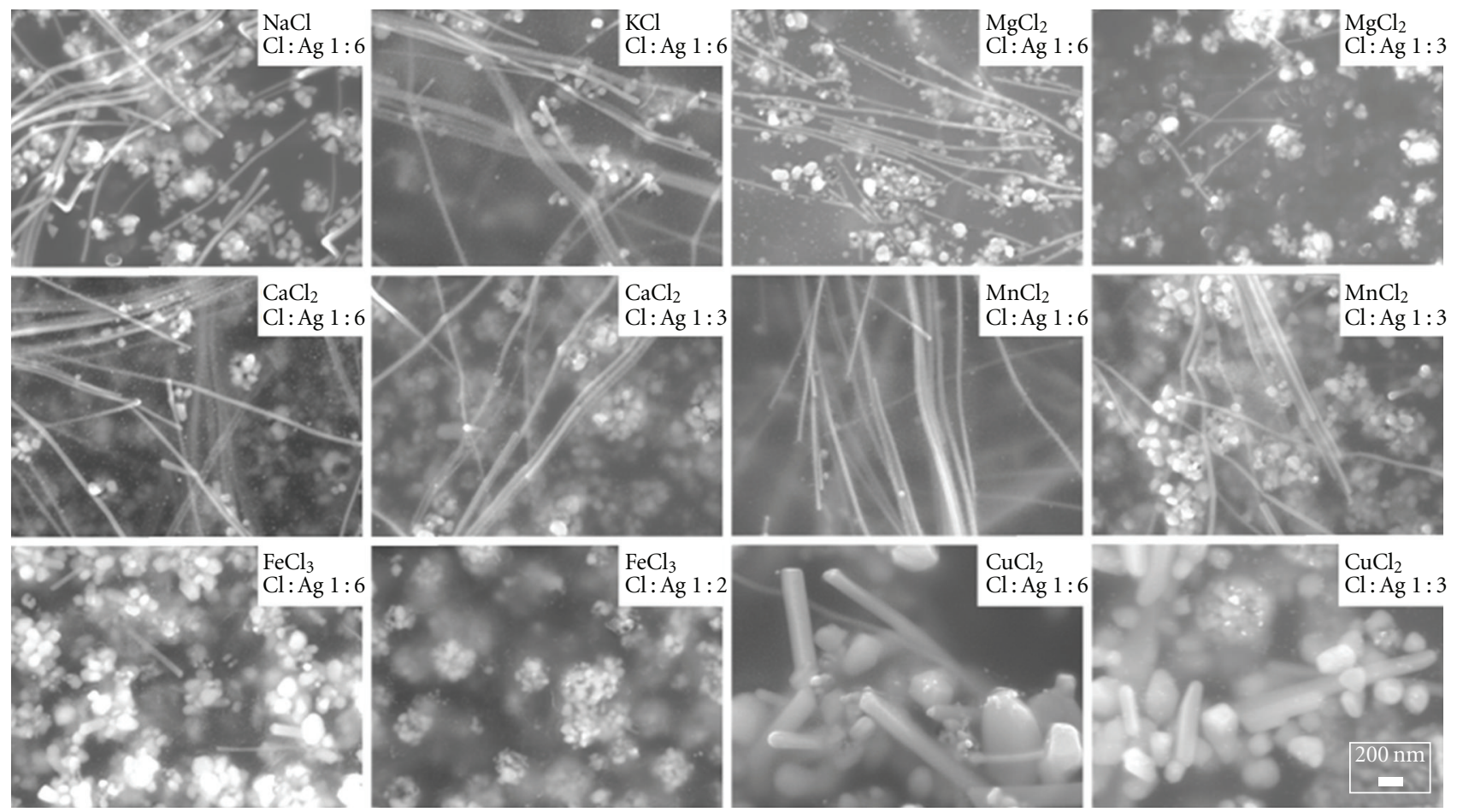

Figure 2: SEM images, magnification $35 \mathrm{k}$ of silver nanomaterials showing the shapes, range of diameters, and lengths produced.

rods [23]. To determine if this effect exists when conducting microwave synthesis, chloride salts of the transition metals $\mathrm{Mn}, \mathrm{Fe}$, and $\mathrm{Cu}$ were evaluated in this work. Table 1 provides the measured diameter, length, and the normalized number of rods obtained when these salts were used in the microwave-assisted polyol process. In contrast to previous work on the traditional polyol process, an increase in rod formation when using $\mathrm{CuCl}_{2}$ and $\mathrm{FeCl}_{3}$ versus the use of $\mathrm{NaCl}$ in the microwave-assisted process was not observed. The rods produced at all concentrations of $\mathrm{FeCl}_{3}$ and $\mathrm{CuCl}_{2}$ tested were fatter, shorter, and fewer in number. In previous studies, the reaction was conducted over a period of several hours, while in the current study the reaction proceeds to completion in $\sim 5 \mathrm{~min}$. The much faster reaction times may 


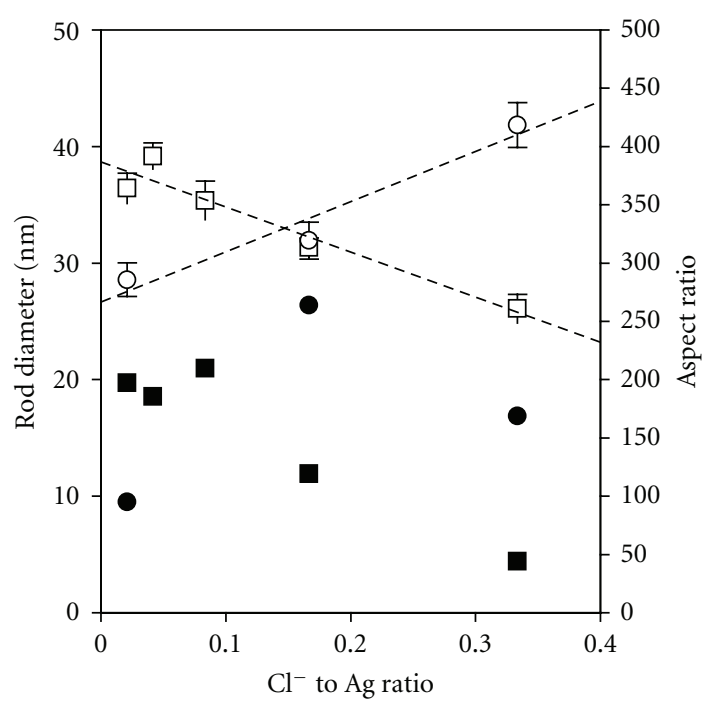

Figure 3: Change in $\mathrm{Ag}$ rod diameter and rod aspect ratio as a function of $\mathrm{MnCl}_{2}$ and $\mathrm{MgCl}_{2}$ concentration. Data for $\mathrm{MgCl}_{2}$ is shown in the open and closed squares while that for $\mathrm{MnCl}_{2}$ is shown in the open and closed circles. Open symbols are the mean rod diameters (error bars are the standard error of the mean), plotted on the left axis, and closed symbols are the aspect ratios, plotted on the right axis.

not allow for oxidative etching to occur at a rate comparable to growth. $\mathrm{FeCl}_{3}$ resulted in relatively short rods with a diameter of $57 \mathrm{~nm}$ and an AR on the order of $9 . \mathrm{CuCl}_{2}$ resulted in similarly short large-diameter rods with an AR on the order of 8 to 23 depending on concentration of the salt. In contrast, $\mathrm{MnCl}_{2}$ resulted in relatively small-diameter rods with $\mathrm{AR}$ on the order of $160-260$ and of the three transition metals evaluated seems the most suitable for the production of high aspect ratio $\mathrm{Ag}$ nanowires using the microwave-assisted process. The use of $\mathrm{MnCl}_{2}$ results in rods with smaller diameters and longer lengths than $\mathrm{NaCl}$ at a similar yield.

To further explore the effect of changing the salt concentration on the rod diameter, several more concentrations of $\mathrm{MgCl}_{2}$ and $\mathrm{MnCl}_{2}$ were evaluated. Figure 3 shows the mean rod diameter obtained as a function of the $\mathrm{Cl}^{-}$to $\mathrm{AgNO}_{3}$ ratio for both $\mathrm{MgCl}_{2}$ and $\mathrm{MnCl}_{2}$. In the case of $\mathrm{MgCl}_{2}$, increased concentration resulted in smaller-diameter rods. However, the rod length was significantly reduced as well resulting in a reduction in AR from 200 to $\sim 50$ over the concentration range evaluated. Different results were obtained when the concentration of $\mathrm{MnCl}_{2}$ was changed. Smallerdiameter rods were obtained at the lowest salt concentration while the rod length and, thus, aspect ratio peaked at the intermediate concentration.

3.2. Effects of Changes in Procedure. Others have found that small changes to the reaction conditions can have significant impacts on the formation of nanoparticles [3, 5-8]. Here we report some effects of reaction conditions on the formation of silver nanorods and wires that we noted during the development of the procedure used to identify the effects of the cation used as reported above. During this development,

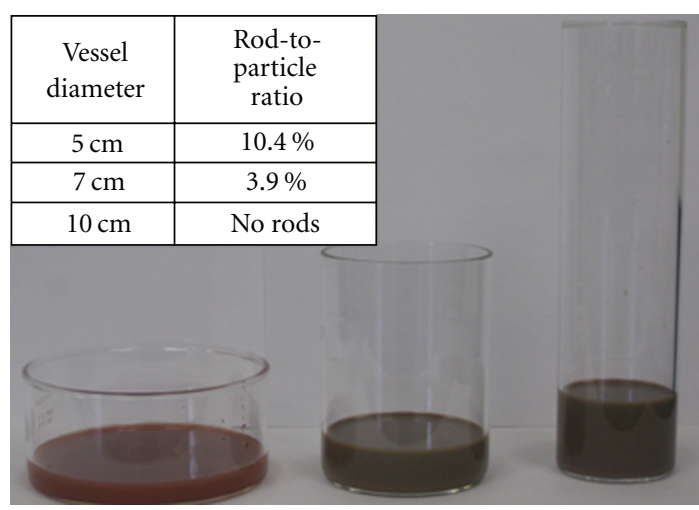

FIGURE 4: Comparison between three container shapes evaluated in initial work. The containers total volume was the same, $300 \mathrm{~mL}$, in all cases.

we noticed two experimental parameters that seemed to have a significant effect on rod formation in the microwaveassisted synthesis process, prereaction conditions, and the shape of the reactor used.

Table 2 shows typical results for five different reaction conditions that were evaluated. The reaction conditions that were varied were the method of mixing the stock solutions together in the reaction vessel, how long this mixing occurred whether or not the solution was purged with $\mathrm{N}_{2}$ to remove dissolved $\mathrm{O}_{2}$, and how soon the microwave heating was initiated after all mixing and purging were completed. Method I was the method ultimately selected to prepare the data shown previously on the influence of salt selection. Increasing the mixing time from a few quick swirls to 2 minutes seemed to increase the yield and the length of the rods formed. Sonication in contrast results in smaller-diameter shorter rods. Eliminating the $\mathrm{N}_{2}$ purge had little effect. However, simply waiting for 10 minutes before starting the microwave had a significant effect on the reaction. No rods were formed; only spherical particles and aggregates were produced.

To the best of our knowledge, there has not been any previous work on the effect of shape of container on the synthesis and yield of the silver nanoparticles. Reaction vessel's size and shape are rarely specified in published methods: Gou et al. used a "flask" [25], Chen et al. used a "three necked flask" [26], and Korte et al. used a "glass vial" [23]. Since the reaction is very temperature sensitive and different container shapes provide a different surface-to-volume ratio and heating path, it was hypothesized that container shape may influence results. Three containers were evaluated. All containers had the same wall thickness and were blown from the same glass. All containers had the same $300 \mathrm{~mL}$ brim full volume and a cylindrical shape but different masses and diameters. The mass of the containers shown in Figure 4 were $146.9 \mathrm{~g}$, $122.8 \mathrm{~g}$, and $110.9 \mathrm{~g}$ for the $5 \mathrm{~cm}, 7 \mathrm{~cm}$, and $10 \mathrm{~cm}$, respectively. The number ratio of rods to spheres, as determined by optical microscopy, is provided in the inset table of Figure 4 . When the vessel with the largest diameter, thus the largest surface area, was used, no rods were found. As the container diameter was decreased, the number of rods increased. To ensure that these results were not simply due to 
TABLE 2: Rod diameter, length, and number of rods produced for several reaction conditions examined. All samples were prepared using KCl as the salt with a $\mathrm{Cl}: \mathrm{AgNO}_{3}$ ratio of $1: 6$.

\begin{tabular}{lcccccccc}
\hline Method & Mixing & $\begin{array}{c}\text { Mixing time } \\
(\mathrm{min} .)\end{array}$ & $\begin{array}{c}\mathrm{N}_{2} \text { gas } \\
(\mathrm{min} .)\end{array}$ & $\begin{array}{c}\text { Microwave start } \\
\text { time }(\mathrm{min})\end{array}$ & Diameter $(\mathrm{nm})$ & $\begin{array}{c}\text { Length } \\
(\mu \mathrm{m})\end{array}$ & $\begin{array}{c}\text { Nominal } \\
\text { AR }\end{array}$ & $\begin{array}{c}\text { No. of rods } \\
\text { I }\end{array}$ \\
II & Hand & 0.25 & 1 & 0 & $35.5(6.4)$ & $9.3(1.4)$ & 261 & $50(6)$ \\
III & Hand & 2 & 1 & 0 & $33.7(8.4)$ & $10.1(2)$ & 300 & $64(8)$ \\
IV & Sonication & 2 & 1 & 0 & $30.1(5.8)$ & $7.3(1.6)$ & 243 & $42(3)$ \\
V & Hand & 0.25 & 0 & 0 & $34.3(5.4)$ & $8.9(2.7)$ & 259 & $47(17)$ \\
\hline
\end{tabular}

the irradiation level not being consistent within the microwave cavity, the reaction was repeated multiple times using the large-diameter vessel at various locations within the cavity. Since rods were not produced at any location when the large-diameter vessel was used, uneven power distribution in the microwave chamber was not the cause of the lack of rod formation. To see if the differences were due to evaporation from the larger surface of the large-diameter containers, a watch glass was used to reduce evaporation from all containers. This did not affect the rate of rod formation. The nanorod-to-nanoparticle ratio for the smaller-diameter vessels remained similar, while the large-diameter vessel failed to produce rods.

Several factors likely contributed to the results. First, the surface-to-volume ratio of the reaction mass may affect both the heat distribution within the volume at short times (before convective heat transfer starts) and the cooling rate of the reaction mass after removal from the microwave. The change in total mass of glass is an increase of $\sim 35 \%$ going from the highest-diameter to the lowest-diameter vessel used in this study. Tests in which reaction was stopped at defined times and the temperature of the dispersion measured with a fast response time thermocouple failed to show any differences in peak reaction temperature or heat up rates between the three reaction vessels evaluated. However, it was noted that the increased free surface area samples resulted in increased cooling rates after the reactor was removed from the microwave. Therefore, cooling rate and the progress of the reaction during cooling may be a factor. Second, vessel geometry affects how the initial reaction is distributed throughout the reactor volume. As the irradiation is attenuated by absorbance by the reactants, the power level drops from the outside of the reaction volume towards the centre of the reactor. This type of temperature differential would not have been detected in the measurements of overall heat up rate performed. One might expect that a more even heating would result in more rods as the processes is nucleated equally everywhere within the reaction volume. However, the container that should have the most even heating of the reactants and the large-diameter vessel resulted in the lowest production of rods. While the source of the effect of container geometry on nanorod yield is not clear, these results highlight that container shape, a parameter not typically included in published methods, can profoundly affect results. The importance of stating container shape in published methods should not be overlooked.

\section{Conclusions}

A range of salts were tested in the microwave-assisted polyol synthesis of silver nanorods. The results indicate that the behaviour of these salts in the microwave-assisted process is different than in reactions in which the heating is conducted over a longer time. Most notably iron and copper salts, which have been shown to dramatically improve the production yield and aspect ratio of silver nanorods produced in the traditional process, were shown to reduce the yield and length and significantly increase the diameter of the rods obtained in the microwave-assisted process. Changing the concentration of manganese chloride and magnesium chloride was a suitable route to control the aspect ratio and diameter of the produced nanorods. In particular manganese chloride can be used to produce rods with similar yields to sodium chloride but with smaller diameter and longer lengths, thus, AR $\sim 30 \%$ higher. The effects of these two cations are directionally different on the rod diameter. These results suggest that, while the microwave-assisted synthesis process is a facile route to nanorods the roles of cations are fundamentally different than those in the traditional polyol process.

\section{Acknowledgments}

This work was supported in part by a grant from the Department of Commerce. Teng Xu's assistance with rod and sphere counts in optical images is appreciated.

\section{References}

[1] C. J. Murphy, T. K. Sau, A. Gole, and C. J. Orendorff, "Surfactant-directed synthesis and optical properties of onedimensional plasmonic metallic nanostructures," MRS Bulletin, vol. 30, no. 5, pp. 349-355, 2005.

[2] C. J. Murphy, T. K. Sau, A. M. Gole et al., "Anisotropic metal nanoparticles: synthesis, assembly, and optical applications," Journal of Physical Chemistry B, vol. 109, no. 29, pp. 1385713870, 2005.

[3] D. K. Smith and B. A. Korgel, "The importance of the CTAB surfactant on the colloidal seed-mediated synthesis of gold nanorods," Langmuir, vol. 24, no. 3, pp. 644-649, 2008.

[4] N. R. Jana, L. Gearheart, and C. J. Murphy, "Wet chemical synthesis of high aspect ratio cylindrical gold nanorods," Journal of Physical Chemistry B, vol. 105, no. 19, pp. 4065-4067, 2001. 
[5] J. Perez-Juste et al., "Electric-field-directed growth of gold nanorods in aqueous surfactant solutions," Advanced Functional Materials, vol. 14, no. 6, pp. 571-579, 2004.

[6] X. C. Jiang, A. Brioude, and M. P. Pileni, "Gold nanorods: limitations on their synthesis and optical properties," Colloids and Surfaces A, vol. 277, no. 1-3, pp. 201-206, 2006.

[7] X. C. Jiang and M. P. Pileni, "Gold nanorods: influence of various parameters as seeds, solvent, surfactant on shape control," Colloids and Surfaces A, vol. 295, no. 1-3, pp. 228-232, 2007.

[8] D. K. Smith, N. R. Miller, and B. A. Korgel, "Iodide in CTAB prevents gold nanorod formation," Langmuir, vol. 25, no. 16, pp. 9518-9524, 2009.

[9] R. Sanci and M. Volkan, "Surface-enhanced Raman scattering (SERS) studies on silver nanorod substrates," Sensors and Actuators, vol. 139, no. 1, pp. 150-155, 2009.

[10] A. Tao, F. Kim, C. Hess et al., "Langmuir-Blodgett silver nanowire monolayers for molecular sensing using surface-enhanced Raman spectroscopy," Nano Letters, vol. 3, no. 9, pp. 1229-1233, 2003.

[11] F. Sun, W. Cai, Y. Li, L. Jia, and F. Lu, "Direct growth of monoand multilayer nanostructured porous films on curved surfaces and their application as gas sensors," Advanced Materials, vol. 17, no. 23, pp. 2872-2877, 2005.

[12] L. Hu, H. S. Kim, J. Y. Lee, P. Peumans, and Y. Cui, "Scalable coating and properties of transparent, flexible, silver nanowire electrodes," ACS Nano, vol. 4, no. 5, pp. 2955-2963, 2010.

[13] B. L. Roos-Kozel and F. M. Casavecchia, "Parameters affecting silver flake and powder performance in silver filled polymers," in Proceedingsof the 34th Electronic Components Conference, pp. 95-100, 1984.

[14] I. Kazeminezhad, A. C. Barnes, J. D. Holbrey, K. R. Seddon, and W. Schwarzacher, "Templated electrodeposition of silver nanowires in a nanoporous polycarbonate membrane from a nonaqueous ionic liquid electrolyte," Applied Physics A: Materials Science \& Processing, vol. 86, no. 3, pp. 373-375, 2007.

[15] J. Xu, J. Hu, C. Peng, H. Liu, and Y. Hu, "A simple approach to the synthesis of silver nanowires by hydrothermal process in the presence of gemini surfactant," Journal of Colloid and Interface Science, vol. 298, no. 2, pp. 689-693, 2006.

[16] S. Cui, Y. Liu, Z. Yang, and X. Wei, "Construction of silver nanowires on DNA template by an electrochemical technique," Materials and Design, vol. 28, no. 2, pp. 722-725, 2007.

[17] K. K. Caswell, C. M. Bender, and C. J. Murphy, "Seedless, surfactantless wet chemical synthesis of silver nanowires," Nano Letters, vol. 3, no. 5, pp. 667-669, 2003.

[18] Y. Xia and Y. Sun, "Large-scale synthesis of uniform silver nanowires through a soft, self-seeding, polyol process," Advanced Materials, vol. 14, no. 11, pp. 833-837, 2002.

[19] B. Wiley, Y. Sun, and Y. Xia, "Polyol synthesis of silver nanostructures: control of product morphology with $\mathrm{Fe}(\mathrm{II})$ or Fe(III) Species," Langmuir, vol. 21, no. 18, pp. 8077-8080, 2005.

[20] B. Wiley, Y. Sun, and Y. Xia, "Synthesis of silver nanostructures with controlled shapes and properties," Accounts of Chemical Research, vol. 40, no. 10, pp. 1067-1076, 2007.

[21] C. Chen, L. Wang, G. Jiang et al., "Study on the synthesis of silver nanowires with adjustable diameters through the polyol process," Nanotechnology, vol. 17, no. 15, pp. 3933-3938, 2006.

[22] D. Chen, X. Qiao, X. Qiu, J. Chen, and R. Jiang, "Convenient synthesis of silver nanowires with adjustable diameters via a solvothermal method," Journal of Colloid and Interface Science, vol. 344, no. 2, pp. 286-291, 2010.
[23] K. E. Korte, S. E. Skrabalak, and Y. Xia, "Rapid synthesis of silver nanowires through a $\mathrm{CuCl}$ - or $\mathrm{CuCl} 2$-mediated polyol process," Journal of Materials Chemistry, vol. 18, no. 4, pp. 437-441, 2008.

[24] D. Adam, "Microwave chemistry: out of the kitchen," Nature, vol. 421, no. 6923, pp. 571-572, 2003.

[25] L. Gou, M. Chipara, and J. M. Zaleski, "Convenient, rapid synthesis of Ag nanowires," Chemistry of Materials, vol. 19, no. 7, pp. 1755-1760, 2007.

[26] D. Chen, X. Qiao, X. Qiu, J. Chen, and R. Jiang, "Convenient, rapid synthesis of silver nanocubes and nanowires via a microwave-assisted polyol method," Nanotechnology, vol. 21, no. 2, pp. 025607/1-025607/7, 2010. 

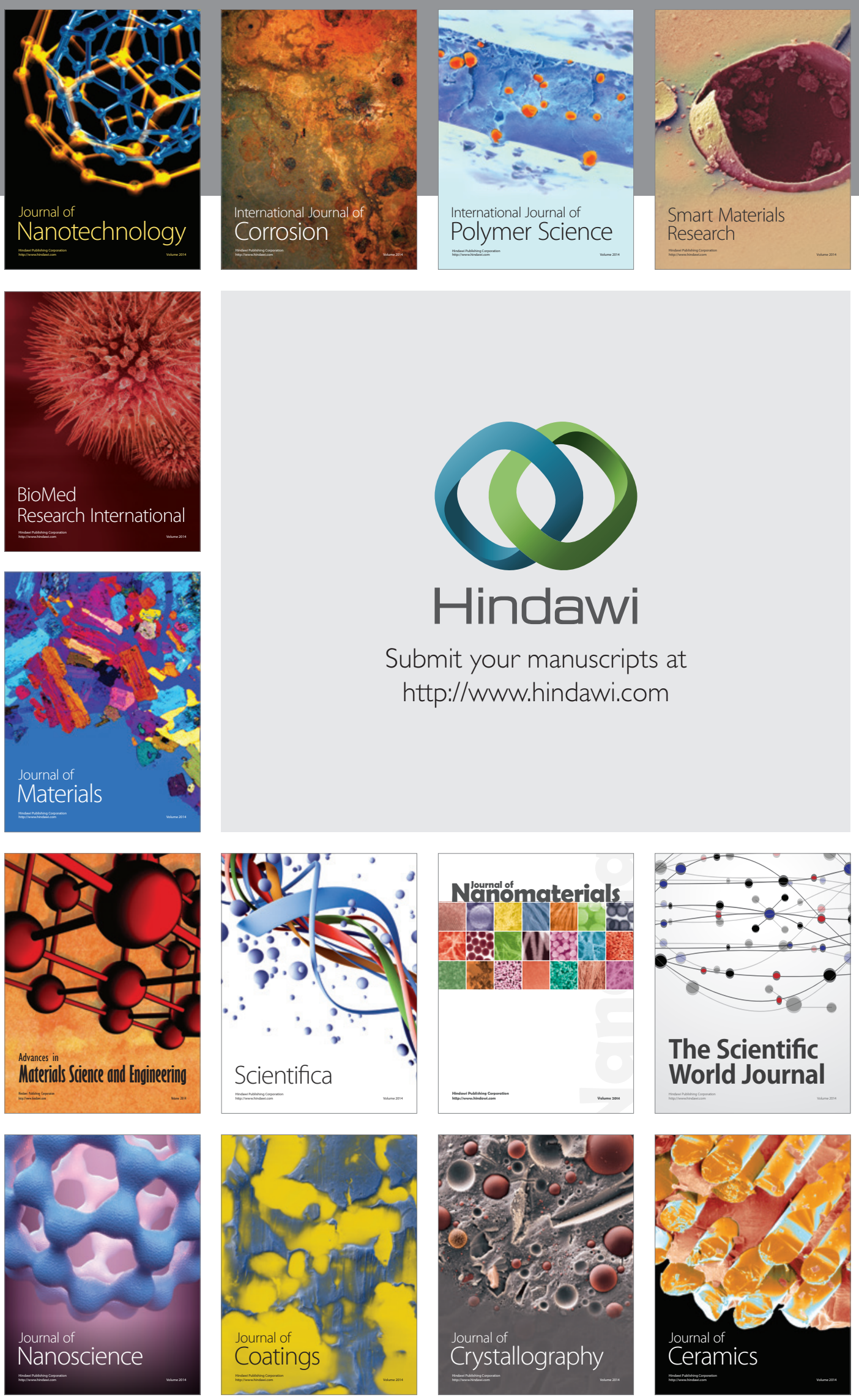

The Scientific World Journal

Submit your manuscripts at

http://www.hindawi.com

\section{World Journal}

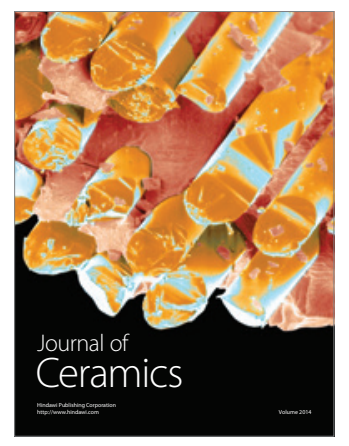

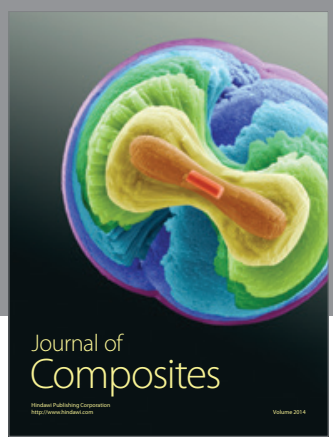
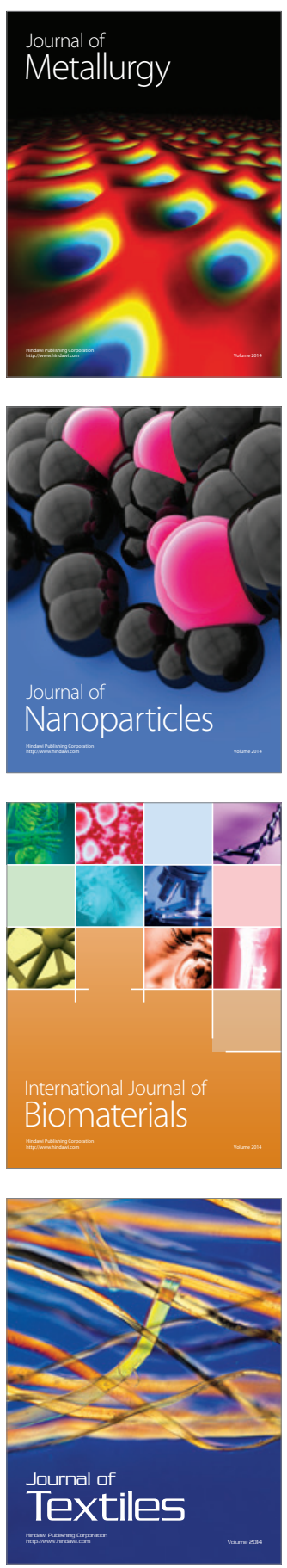